\title{
Cultura, transformación urbana y empoderamiento ciudadano frente a la gentrificación. Comparación entre el caso de Getsemaní (Cartagena de Indias) y el Raval (Barcelona)
}

Joaquim Rius-Ulldemolins. Universitat de València, València, España. Ladys Posso Jiménez. Universidad de Barcelona, Espańa.

RESUMEN | La cultura se ha convertido en un elemento esencial en los procesos de transformación urbana, especialmente en los barrios céntricos de las ciudades históricas. Ello se explica por lo decisivo de su rol en cuanto a fomentar el consumo y la marca territorial en el marco de la globalización de flujos económicos y turísticos. Este papel de la cultura en la refuncionalización del espacio urbano ha sido reiteradamente criticado por diversos autores. Sin embargo, también se plantea que la cultura puede contribuir a revalorizar los barrios marginales construyendo una imagen positiva, y a empoderar a la ciudadanía contra la gentrificación. Asimismo, como se analizará en el caso de Getsemaní y del Raval, la alianza de los sectores creativos con habitantes tradicionales permite generar discursos y planes alternativos a la expulsión y estandarización de espacios urbanos históricamente populares, creando una identidad de barrio compartida y basada en el patrimonio inmaterial existente.

PALABRAS CLAVE | cultura urbana, gentrificación, participación ciudadana.

ABSTRACT | Culture has become an essential element in the processes of urban transformation, especially in the central districts of historical cities. This is explained by the crucial role that culture plays in promoting consumption and territorial marking in the context of globalization of economic and tourist flows. The role of culture in the revamping of urban space has been repeatedly criticized by several authors. However, it is also suggested that culture can contribute to revalue deprived districts by creating positive images and empower citizens against gentrification. Also, as it will be analyzed in the case of Getsemani and Raval, the alliance of creative industries with traditional inhabitants allows generating discourses and plans alternative to expulsion and standardization of historically popular urban spaces, creating a shared neighborhood identity based on the existing intangible heritage.

KEY WORDS | urban culture, gentrification, citizen participation. 


\section{Introducción}

La centralidad de la cultura en los procesos de transformación urbana es un hecho crecientemente analizado y documentado en los países avanzados (Montgomery, 2003) y también más recientemente en algunos países emergentes (Wu, 2005). Desde los pioneros estudios de los ańos ochenta en Estados Unidos o Gran Bretańa (Bianchini, 1991; Zukin, 1989), la transformación de barrios céntricos en clústeres de actividad cultural ha sido analizada de una forma positiva, en tanto factor de crecimiento económico y de empleo (Markusen \& Schrock, 2006; Williams \& Currid-Halkett, 2011), o con un enfoque crítico, como generadora de gentrificación y exclusión urbana al servicio de la reconversión neoliberal de la ciudad (Harvey, 2005; Peck, 2005).

Por otra parte, diversos autores han seńalado la creciente importancia de las industrias creativas y el turismo en la economía urbana y, en este caso, la relevancia de la generación de marcas territoriales para promover las ciudades (Evans, 2003; Pike, 2011). En este contexto, los barrios céntricos de las ciudades que apuestan por la economía creativa o el turismo cultural se están convirtiendo en importantes factores de atracción y diferenciación respecto de otros productos y destinos (Rius-Ulldemolins, 2014). Conscientes de ello, las industrias creativas y las empresas turísticas están generando mayor presión sobre estos barrios para adaptarlos a sus necesidades (Degen \& García, 2012). A contramano, también estos procesos de gentrificación están formando movimientos de resistencia vecinal, en los cuales los nuevos vecinos -entre los que se encuentran creadores atraídos por la centralidad y el patrimonio cultural del barrio- originan alianzas contra los procesos de expulsión y estandarización del diseño urbano y su contenido sociocultural (Julier, 2005; 2011). En estos movimientos, un factor central en disputa lo constituye la generación de un relato que reivindique los elementos de patrimonio material (forma de los edificios y trama urbana) e inmaterial del barrio (identidad, estilo de vida) y favorezca su preservación.

Frente a tal realidad, con este artículo se pretende demostrar, por una parte, la formación de coaliciones de artistas y comunidad local frente a la gentrificación; y por otra, la falta de consenso entre instituciones, comunidades, agentes económicos y artistas en el desarrollo de procesos de regeneración urbana basados en la cultura. En este sentido, el análisis intenta ahondar en la composición de las coaliciones y en aquellas causas de desacuerdo entre los agentes que impiden avanzar en una gobernanza y sostenibilidad de los procesos, que permitan combinar desarrollo económico y turístico, con mantenimiento de la identidad y de la población local.

Hemos elegido para analizar estos procesos los casos del Raval (Barcelona) y Getsemaní (Cartagena de Indias), barrios donde se han desarrollado procesos de regeneración urbana en los que han desempeñado un rol central la cultura y los creadores. Las dos ciudades corresponden al perfil de ciudad grande, capital regional -sin ser capitales de un Estado-nación, con todo lo que ello comporta a nivel socioeconómico y político-, siendo casos en los que el gobierno local ha hecho una apuesta por el turismo y diseñado una estrategia de city branding acorde (Brida, Bukstein, Garrido \& Tealde, 2010; Rius-Ulldemolins, 2014). Asimismo, los barrios elegidos son céntricos, de relevancia histórica pero antiguamente marginales, y casos ejemplares en los que la cultura desempeña un papel de atracción de las industrias culturales y turísticas 
(por lo tanto, generando gentrificación), aunque a la vez está facilitando procesos de participación y empoderamiento ciudadano. Veremos, sin embargo, que en uno de los casos, el Raval de Barcelona, las administraciones públicas han cumplido una labor más activa en las políticas urbanas y sociales y en la creación de espacios de gobernanza del proceso de regeneración urbana y los usos de la cultura para este fin que en Getsemaní, mientras en este último caso el proceso de regeneración urbana ha sido protagonizado por agentes económicos y turísticos, con la iniciativa para el desarrollo de coaliciones antigentrificación en manos del tercer sector.

A nivel metodológico, el análisis del proceso de transformación del Raval se apoya en un trabajo de campo de 35 entrevistas, tres grupos de discusión y seis meses de observación del barrio (citación anonimizada) ${ }^{1}$. Este trabajo ha sido posteriormente actualizado con seis entrevistas a agentes culturales del barrio en el marco del proyecto de investigación (referencia anonimizada), que validan los datos y observaciones realizadas anteriormente. En tanto, el análisis del barrio Getsemaní se ha realizado a partir de cuarenta y nueve entrevistas cualitativas y la observación en la zona durante nueve meses (citación anonimizada) ${ }^{2}$, que han sido incorporadas al análisis a partir de un análisis de contenido ${ }^{3}$.

\section{Creación de clústeres culturales, gentrificación urbana y movimientos sociales}

De forma creciente, se ha tomado conciencia de que la clusterización cultural genera beneficios por la concentración y la densidad de intercambios entre agentes culturales (Markusen, 1996; Markusen \& Gadwa, 2010), y que su importancia no se deriva solamente de factores infraestructurales (Scott, 2000), sino de las relaciones sociales formales e informales que permiten conformar una escena creativa (Currid, 2007; Currid \& Williams, 2010). Esta mayor conciencia se ha transformado en políticas de incentivo de las industrias creativas o de la ciudad creativa, y de la generación de clústeres culturales en sus diversas formas: de industrias culturales,

1 El trabajo de campo se desarrolló en el marco de la investigación "Museos y barrios artísticos: arte público, artistas, instituciones", proyecto financiado por el Ministerio Economía y Competitividad, Plan Nacional de I+D+I. (Ref. HAR2or2-38899-Co2-OI). Las entrevistas se realizaron con responsables políticos y de agencias públicas (10), representantes de movimientos u organizaciones sociales (15), representantes o miembros de entidades culturales (10). Se realizaron tres grupos de discusión, uno conformado por antiguos residentes (nacidos en el barrio o con más de cinco ańos de residencia en él), un segundo grupo compuesto por nuevos residentes (menos de cinco ańos en el barrio) y un tercero integrado por Amigos del Centro de Cultura Contemporánea de Barcelona, para recoger la visión de los usuarios del barrio.

2 Para las entrevistas del caso Getsemaní, se seleccionaron habitantes tradicionales (10), nuevos residentes (6), miembros de instituciones, asociaciones cívicas y culturales (11), artistas (17), restauradores (2) e investigadores (3). También se recurrió a la elaboración de planos y fotos que permitieran el registro de la ubicación espacial, dinámicas socioculturales y comerciales y el mapeo de los sectores artísticos y artesanales del barrio.

3 Los resultados de las entrevistas y grupos de discusión han sido transcritos, analizados de forma sistemática y utilizados para fundamentar el análisis, pero no son citadas de forma literal, para evitar una longitud excesiva del artículo. Análisis detallados de los agentes sociales locales se pueden consultar en las monografías publicadas por los autores en el caso del Raval y Getsemaní (citaciones anonimizadas). 
distritos de consumo cultural o escenas culturales (Zarlenga, Rius-Ulldemolins \& Rodríguez Morató, 2013).

No obstante lo anterior, de forma creciente se ha señalado el impacto elitizador a nivel social, y gentrificador en la esfera urbana, de la ascendente instrumentalización económica y social de la cultura y de sus productores como un fenómeno ligado al capitalismo neoliberal; esto es, el papel de la cultura en estrategias de regeneración urbana orientadas al branding e intereses del mercado inmobiliario (Balibrea, 2004; Bianchini, 1993; Borja, 2010; Zukin, 1989; Insulza, 2012) y a la elaboración de un discurso sobredimensionado acerca de la capacidad de la cultura para afrontar problemas de orden social (Belfiore, 2002).

Podríamos decir que la problemática a la que hacemos referencia se resume en la tensión provocada por el debilitamiento de las políticas dirigidas al bienestar de quienes habitan las ciudades (Jordán \& Carbonetti, 2007) y, correlativamente, el fortalecimiento de las encaminadas a posicionar a las ciudades en un mercado global entre urbes, altamente competitivo (Mendes, 2007). Esto, en un escenario de clara regresión de los mecanismos de redistribución estatal y del avance de una lógica de mercado como principio configurador de la vida social y el gobierno de las ciudades (Harvey, 1989) que irrumpe con fuerza desde finales de los ochenta en el contexto europeo. La orientación emprendedora se ha expresado a nivel político en mecanismos de gobernanza, mayor participación del sector privado empresarial y en una limitada participación de la ciudadanía (Blakeley, 2005), que ha llevado a algunos autores a destacar la importancia de una ciudadanía crítica para el desarrollo de una gobernanza más democrática y empoderadora (Geissel, 2008).

En este nuevo escenario de pugna entre el mercado, la ciudadanía y la burocracia estatal para desarrollar y controlar los nuevos marcos innovadores de gobernanza (Swyngedouw, 2005), se han destacado los efectos empoderadores de la participación de la ciudadanía en los procesos de redefinición urbana y la importancia de tejer alianzas entre los habitantes tradicionales y los nuevos vecinos, los movimientos sociales tradicionales (asociaciones vecinales, sindicatos) y los nuevos movimientos sociales (Parés, Bonet-Martí \& Martí-Costa, 2012). Esta alianza debe basarse en generar un nuevo imaginario común, una nueva marca de barrio alternativa a la banalización neoliberal, que conjugue la identidad tradicional con los nuevos usos y creaciones de la economía posfordista (Lloyd, 2010; Rius-Ulldemolins, 2014).

En esta línea se sostiene que, a través del desarrollo de proyectos alternativos de identidad de barrio y de revalorización de su cultura, los creadores pueden desempeñar un papel importante en la formación de una subcultura urbana alternativa a los valores dominantes (Fischer, 1995) y en forjar nuevas coaliciones antigentrificación. Asimismo, que disponen de un capital simbólico y cultural que les permite la generación de planes urbanos alternativos y de espacios de esperanza para los habitantes más desfavorecidos, amenazados por la expulsión urbana y exclusión social en estos barrios céntricos y de raíz popular, afectados por los procesos de refuncionalización urbana neoliberal (Novy \& Colomb, 2013). Es esta una perspectiva que puede abrir horizontes más sostenibles e inclusivos de regeneración urbana que los ligados exclusivamente al mercado (Kagan \& Hahn, 2011). 


\section{Cultura, transformación urbana y empoderamiento ciudadano frente a la gentrificación: el caso de Getsemaní (Cartagena de Indias)}

\section{Cartagena de Indias: patrimonio cultural}

Finalizando el siglo XIX, el casco urbano fundacional cartagenero comprendía un cordón de murallas y fuertes en torno a su núcleo urbano, que concentraba lo que se definía como población de Cartagena (Aguilera \& Meisel, 2009) ${ }^{4}$, junto con el arrabal de Getsemaní. Asimismo, entre 1880 y 1924 los gobiernos locales, argumentando la recuperación sanitaria del área y la expansión del trazado metropolitano, emprendieron la demolición sistemática del entramado fortificado. Esta fue detenida por legislación prohibitiva del gobierno nacional y fuertemente criticada por un sector de la elite local, que reivindicaba el arte monumental y el legado hispánico del conjunto.

En la segunda mitad del siglo xx, el complejo amurallado recibió las distinciones de Patrimonio Nacional de Colombia (1959) y Puerto, Fortalezas y Conjunto Monumental de Cartagena de Indias como Patrimonio de la Humanidad (1984) por la Unesco. En las décadas de 1960 y 1970, se erigió en punta de lanza de la política turística nacional iniciada durante la presidencia de Carlos Lleras Restrepo (Ávila, 2011) y en polo importante de turismo internacional, potencializado en la última década (Corporación de Turismo de Cartagena de Indias, 2014). Hoy es un polo de atracción especialmente relevante dentro de la ruta de cruceros del Caribe, que aporta casi trescientos mil visitantes anuales de un elevado poder adquisitivo (Brida et al., 2010), fenómeno que ha generado un creciente desarrollo comercial y hotelero, especialmente en el centro histórico.

\section{Origen y evolución del barrio Getsemaní:}

\section{del período colonial a la degradación urbana}

La primera población de Getsemaní estuvo conformada por indígenas kalamaries, que llegaron en las invasiones caribes de Venezuela (Díaz \& Paniagua, 1993). Tiempo después de la fundación hispánica de Cartagena el terreno le fue adjudicado al músico ibérico Juan Pérez de Materano, mientras en la segunda mitad del siglo Xvi se producía el desarrollo urbanístico de la ciudad, con el trazado de un núcleo amurallado del que Getsemaní constituye su parte externa. En este espacio urbano extramuros se asentaron inmigrantes con fuentes de trabajo en el contiguo puerto marítimo, en contraste con la población del sector amurallado, encomenderos y profesionales espańoles con posiciones destacadas.

Con la consolidación de Cartagena de Indias como gran puerto comercial de esclavos, Getsemaní presentaba una posición estratégica privilegiada; integrado como otro barrio de la ciudad en el siglo xviI, su población había aumentado y se había diversificada: tratantes de esclavos, marineros y artesanos cuyos oficios se relacionan con la reparación de naves (Lemaitre \& Palmeth, 2001). Ante los continuos ataques de piratas y corsarios a la ciudad, se hizo necesario el reforzamiento

Durante la Colonia, los continuos ataques marítimos a la ciudad forzaron a las autoridades españolas a impedir el poblamiento de los alrededores amurallados. 
amurallado y militar, para lo cual arribaron destacamentos militares antillanos, entre los que el cubano Pedro Romero sobresale, junto con los artesanos del barrio, como importante héroe en la independencia colombiana, reivindicado hoy en día como patrimonio de la memoria de los getsemanicenses.

A finales del siglo xix, se produjo una fuerte inmigración de sirio-libaneses, que se ubicaron en las calles Larga y Media Luna de Getsemaní. Instalaron comercios en las plantas bajas de las residencias, sumándose así a las actividades económicas del puerto, mientras las plantas superiores eran ocupadas como lugar de habitación. La vocación comercial del vecindario se consolidó con la inauguración en 1904 del mercado público de la ciudad en el perímetro del barrio. Paralelamente se desarrollaba en el lugar una intensa vida cultural, con la instalación de ocho teatros y la construcción del parque del Centenario; este, y el Camellón de los Mártires, resultaron importantes espacios de encuentro y tertulia para los cartageneros (Ballestas, 2008). En la segunda mitad del siglo xx se produjo un largo proceso de marginalización del barrio, con la desaparición paulatina de actividad cultural en los teatros, la suspensión de actividades recreativas en el parque del Centenario y el cierre del mercado público, proceso marcado por la inseguridad, el tráfico de estupefacientes y la prostitución.

La naturaleza grupal de las viviendas getsemanicenses y su condición popular (con excepción de las casas altas, que constituían el 9\% del stock inmobiliario) invitaban a la vida en comunidad; el hecho de que las familias compartieran espacios para servicios cotidianos, especialmente en las tipologías arquitectónicas de pasajes y accesorias, propició el tejido de una fuerte red social y sentido comunitario, que se vio afectado en el período de marginalización del barrio. A fin de contrarrestar esta creciente conflictividad social, se desarrollaron diversos proyectos cívicos y culturales para el rescate de los valores y la memoria barrial, que permitieron el surgimiento -abanderado por la Fundación Gimaní Cultural- del Cabildo de Getsemaní, expresión simbólica, festiva y de cohesión social celebrada anualmente, que trasciende los límites del vecindario con notable impacto en toda la ciudad.

\section{FIGURA 1 Mural en la calle La Sierpe}

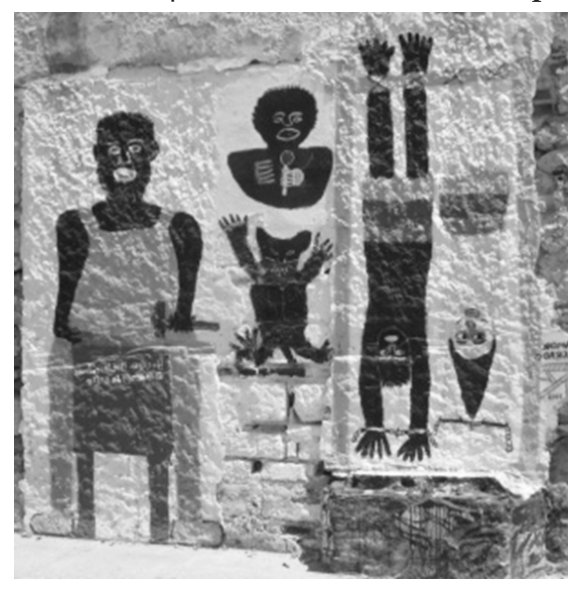

FUENTE FOTOGRAFÍA DE LOS AUTORES 
En Getsemaní, las calles, esquinas y plazas constituyen lugares de encuentro y tertulia: en calle Lomba y callejones Ancho y Angosto (figura 3) se acentúa este vivir en la calle, siendo el espacio de encuentro social por excelencia la plaza de la Trinidad que, a modo de corazón del barrio, aglutina las expresiones generacionales, sociales y culturales, resultando lugar de interés para el turismo, artistas consagrados y emergentes que hallan, en sus manifestaciones culturales, inspiración para sus obras (figuras 1 y 2).

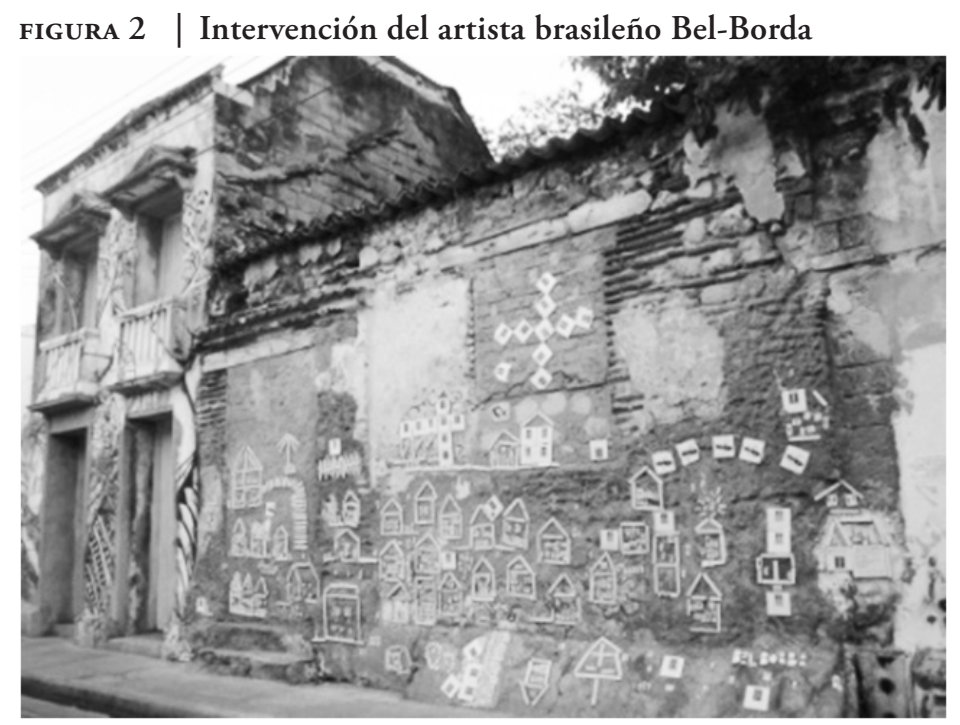

FUENTE FOTOGRAFÍA DE LOS AUTORES

Getsemaní como barrio cultural: transformación urbana y gentrificación

La expresión gentrification, originada en el contexto anglosajón de los ańos sesenta para referirse a fenómenos de desplazamiento de una población original en un sector a favor de otra población que no es originaria del lugar y procede de una clase socioeconómica generalmente más alta (Glass, 1964), en América Latina se relaciona directamente con la retirada del sector público del mercado de la vivienda a partir de los años setenta (Harvey, 2005). Autores como Carrión (2007) aluden a ese proceso como recambio poblacional con la finalidad de que la población de bajos ingresos ceda su espacio a la de ingresos altos, abogando por el no traspaso acrítico de conceptos como ese. Carrión acuña el término boutiquización para mencionar específicamente el cambio de usos de suelo residencial a comercial y administrativo, con ventajas económicas, en que centros históricos son copados por restaurantes, hoteles y boutiques.

El fenómeno no se presenta con las mismas características y dimensiones en los distintos países del Cono Sur. Contreras (2011) y De Mattos et al. (2005) lo asumen como sinónimo de elitización; Casgrain y Janoschka (2013) ponen el puntero en la reconquista de las áreas centrales y consolidadas de las ciudades por el poder económico; Insulza $(2012,2014)$ idea la locución latinogentrificación, sustitución de la 
tipología residencial existente por una nueva tendencia de viviendas, edificios de mediana y gran altura para el caso de Santiago de Chile. Se destaca la gentrificación simbólica para el centro histórico de México, D.F. (Janoschka et al., 2014; Salinas, 2013 y Delgadillo, 2009), con el empleo de políticas neoliberales que restauran el patrimonio arquitectónico para turistas, elites y la creciente clase media, facilitando la expulsión de vendedores ambulantes. En Río de Janeiro, en tanto, el fenómeno se potencia con la realización de megaeventos (Contreras, 2014; Ferreira, 2014 y Makhlouf, 2014), como el Campeonato Mundial de Fútbol del año 2014, fomentándose el desplazamiento de residentes en favelas, reurbanizadas por su cercanía a lugares de eventos o vistas privilegiadas. Para el caso cartagenero, tempranamente Díaz y Paniagua (1994) exponen el fenómeno en el barrio San Diego, alertando sobre la necesidad de que se revitalizara integralmente.

Antes de la declaración de Cartagena de Indias como Patrimonio de la Humanidad en la década de 1980, los inmuebles del centro histórico se encontraban en estado de deterioro (Caraballo, 2000), lo que Vásquez Montalbán (1973), aludiendo a enclaves antiguos, describiría como pobreza con patina histórica. Con la declaratoria de la Unesco, inversores privados iniciaron la compra de residencias en los barrios San Diego y El Centro, generándose paulatinamente una reestructuración funcional (Doratli, 2005) con nuevos usos y actividades económicas, y la consiguiente alza de los costos inmobiliarios. Al agotarse la oferta en estos barrios céntricos, en la última década el foco de interés ha recaído en Getsemaní, presentándose una disminución significativa de la población originaria. En el año 2012, la Asociación de Vecinos del barrio realizó un censo poblacional que evidencia la permanencia de $28 \%$ de los residentes tradicionales, adelgazándose el porcentaje a $16,7 \%$ en la actualización del año 2013 (Ferrer \& Morillo, 2013). Asimismo, las cifras censales revelan que los vecinos se encuentran en situación económica precaria: $61 \%$ de las familias debe subsistir con ingresos mensuales iguales o inferiores a 245 euros $^{5}$ y $40 \%$ de ellas comparte su vivienda con otra o más familias. Ello pone de manifiesto que el proceso de regeneración del barrio no ha aportado a los raizales. Ha sido ocupado, de manera más tardía pero más depredadora que en el casco histórico, por hoteles de alta gama y bares (figura 3), que se han instalado en residencias y espacios con vocación cultural o educativa, como los antiguos cines del barrio y claustros, generando un proceso de expulsión de la población tradicional y de apropiación del barrio por parte de agentes económicos y turísticos externos.

Frente al fenómeno de gentrificación, los artistas expresan sus críticas en trabajos de street art, con principales motivos de reivindicación en la evocación de héroes locales de la independencia (invisibilizados por la historia oficial), protestas contra el alza de impuestos y la resistencia de los vecinos al desplazamiento poblacional (figuras 4 y 5). Agremiaciones cívicas y culturales del barrio, como la Asociación de Vecinos, la Junta de Acción Comunal, la fundación TuCultura y el movimiento Orgullosamente Getsemanicenses, entre otras, realizan acciones para concienciar a los habitantes de la gravedad del fenómeno; sin embargo, no ignoran que un 
número sustancial no es propietario de inmuebles ${ }^{6}$ y que, aun siéndolo, sus integrantes presentan necesidades básicas insatisfechas, con tendencia creciente a vender.

FIGURA 3 | Mapa de comercios y mapa de artistas en el barrio Getsemaní (2013)
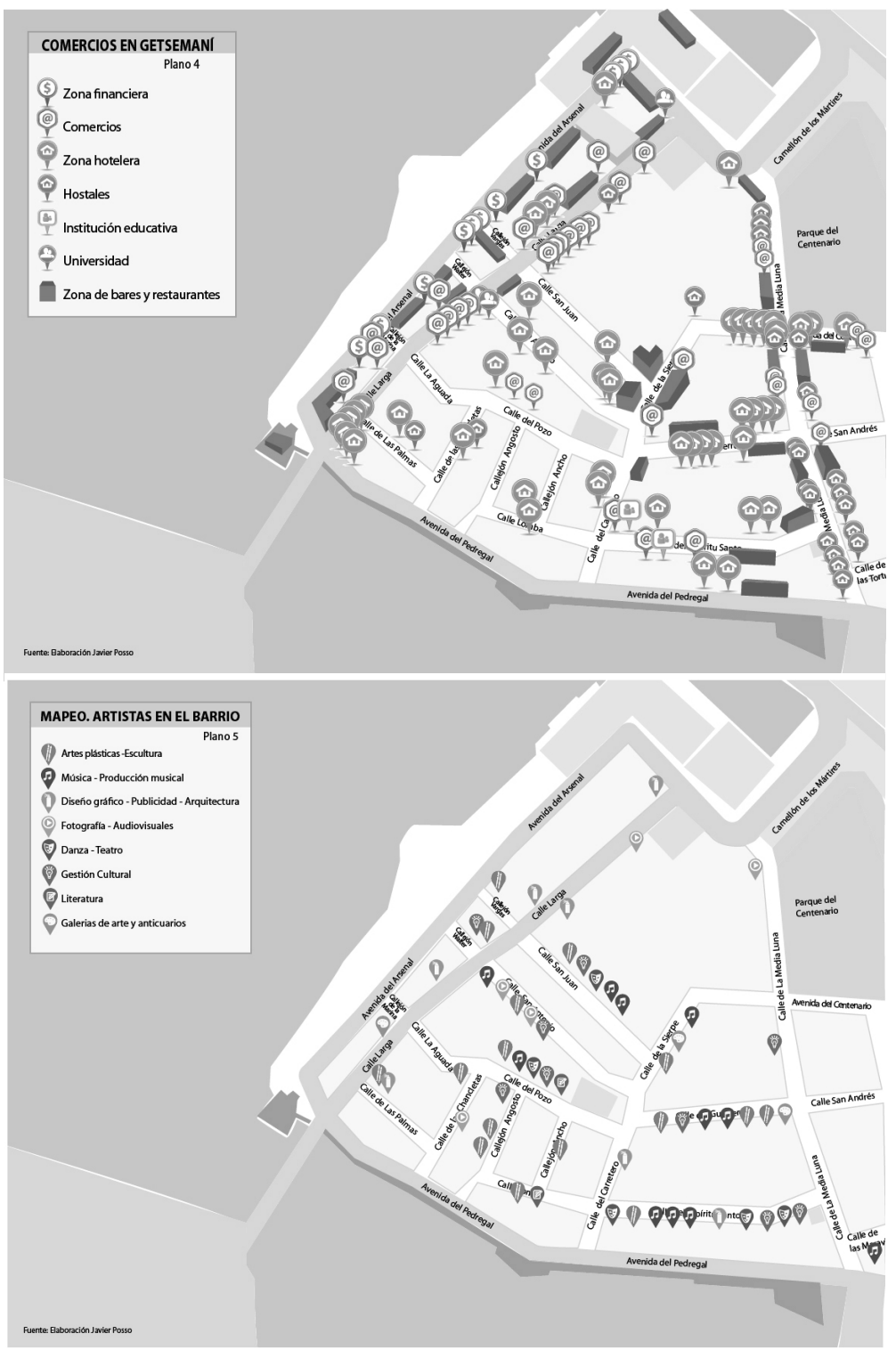

FUENTE MAPA ELABORADO POR LOS AUTORES

$6 \quad$ El 56\% de los residentes no son propietarios; 30\% están en condición de arrendatarios; presentan litigios por escrituración o herencia, $2 \%$ y $9 \%$, respectivamente; $10 \%$ son poseedores y $5 \%$ en ninguna de las anteriores condiciones. Fuente: Censo poblacional 2012. 
FIGURA 4 | Denuncia al desplazamiento poblacional

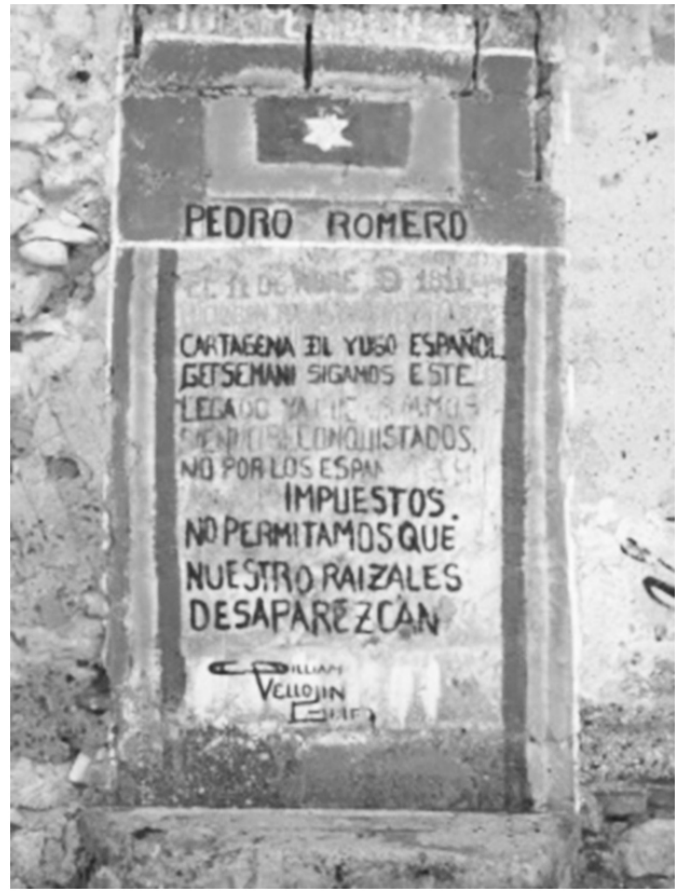

FUENTE FOTOGRAFÍA DE LOS AUTORES

FIGURA 5 | Grafiti: Primero los ciudadanos (...)

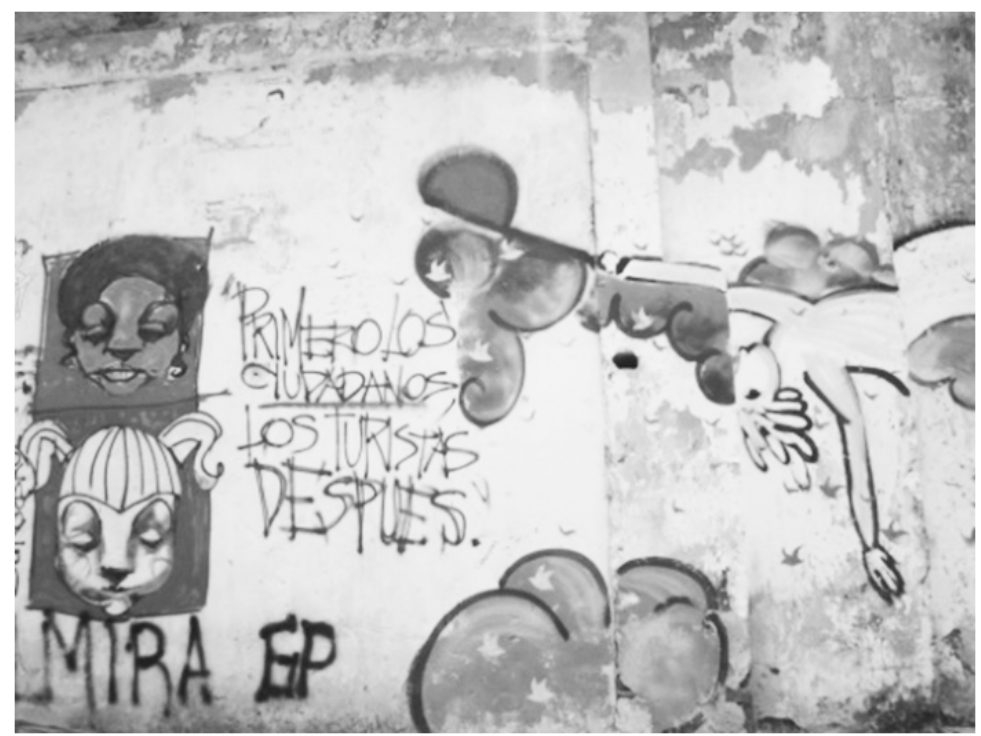

FUENTE FOTOGRAFÍA DE LOS AUTORES 


\section{Participación y empoderamiento ciudadano frente a la gentrificación}

La ciudad se encuentra dividida administrativamente en localidades. El gobierno local se ve representado en Getsemaní por el alcalde de la Localidad Histórica y del Caribe Norte, pero la comunidad es encabezada por agremiaciones cívicas de base que promueven el sentido de pertenencia entre los vecinos frente a las dinámicas gentrificadoras. La Asociación de Vecinos y la Junta de Acción Comunal impulsan valores comunitarios y sirven de enlace con comerciantes y hoteleros en la búsqueda de la inserción laboral de residentes. No obstante, la desunión, y en no pocas oportunidades el desinterés de los habitantes por la problemática, dificultan la consolidación de acciones afirmativas.

Algunas organizaciones, como TuCultura y Chitiá Tours, formulan proyectos que tienen por objetivo convertir el turismo cultural en alternativa económica para los getsemanicenses, a través del involucramiento de la comunidad en la cadena productiva y de valor. Otros procesos, como el proyecto Memorias de la Libertad III ${ }^{7}$, financiado por el Ministerio de Cultura colombiano y ejecutado por la Asociación de Vecinos, han permitido la realización del censo poblacional y establecer preliminarmente datos estadísticos que evidencian la penetración del fenómeno de gentrificación del sector, su complejidad, las condiciones socioeconómicas de sus habitantes; $y$, junto con ello, avanzar en acciones afirmativas de reconocimiento identitario, como cartografías, piezas audiovisuales, archivos fotográficos e intervención en fachadas, y en la promoción de actividades culturales arraigadas en el imaginario barrial de Getcinema, un cine móvil que se instala en calles del barrio, proyectando películas de contenido social y escenas cotidianas de Getsemaní que develan sus principales valores.

Es así que los núcleos de la vida cultural del barrio no se desarrollan a partir del Estado, sino que se conservan por la dinámica propia de sus habitantes: la avenida del Pedregal, una arteria que bordea el barrio y de tráfico regular, ante la ausencia de escenarios deportivos, es cerrada por los vecinos los domingos para un torneo de bola de trapo, deporte similar al béisbol que utiliza una pelota fabricada artesanalmente a partir de calcetines. Alrededor de este evento se integran diversos géneros y grupos etarios, teniendo como escenario natural la calle y las fortificaciones que la rodean.

\section{Cultura, transformación urbana y empoderamiento ciudadano frente a la gentrificación: el caso del Raval (Barcelona)}

\section{Barcelona, modelo de ciudad y política cultural y génesis sociourbana del barrio del Raval}

Durante la segunda mitad del siglo xix y el primer tercio del siglo xx, Barcelona experimentó un vertiginoso desarrollo industrial, que la llevó a convertirse en una gran ciudad moderna. Fue la acción concertada de las elites locales y del poder local

7 Respecto del proyecto Memorias de la Libertad III, véase http://www.tres.memoriasdelalibertad. org/\#proceso. Sobre el ciclo Memorias de la Libertad, allí se indica: "Estos ciclos respondieron a la apuesta por explorar nodos simbólicos que sintetizaran de alguna manera las transformaciones históricas, urbanísticas, sociales y culturales de Getsemaní. Asimismo, las actividades realizadas buscaron generar estrategias visuales y de enunciación que le permitieran a los participantes visibilizar la problemática de su territorio y, que al mismo tiempo, se convirtieran en acciones de resistencia y defensa del mismo”. [N. de E.] 
la que lideró este proceso: la que creó servicios básicos e instituciones de prestigio, y también la que promovió grandes eventos, como las Exposiciones Universales de 1888 y 1929, hitos decisivos en la internacionalización de la ciudad. Esta singular tradición de activismo mancomunado de las elites y el poder local resurgió al recuperarse el margen de maniobra democrática y se convirtió en un activo fundamental de la ciudad ante los nuevos y urgentes retos que la crisis del modelo fordista planteaba. Fue así como en los años ochenta Barcelona desarrollaría uno de los modelos más avanzados de ciudad emprendedora (Marshall, 1996).

El Raval es un barrio céntrico de Barcelona, encajado entre las Ramblas y el trazado de la tercera muralla de la ciudad. Fue urbanizado en la primera mitad del siglo XIX, cuando se establecieron las primeras industrias y edificios de viviendas baratas para la clase trabajadora. El nombre del Raval es una invención ${ }^{8}$ de las administraciones en los años setenta, asignado en un intento de evitar los nombres estigmatizados de barrio Chino, Xino, Distrito V u otros (Villar, 1997), que se asociaban a marginalidad, prostitución o drogadicción. Además, el nombre Xino evoca también el pasado proletario del barrio, el de las luchas anarquistas, el barrio bohemio de principios de siglo (Aisa \& Vidal, 2005). Esta tradición de barrio obrero y bohemio fue reprimida por el régimen franquista y de todo ello solo quedó el tráfico de drogas y la prostitución de calle. Así pues, en los inicios del período democrático, el Raval se encontraba en un proceso de degradación urbana intenso, y desde 1970 hasta el inicio de la reforma en 1986, perdió el 40\% de la población (Subirats \& Rius, 2008). Es decir, cuando empezó la reforma, el Raval ya había perdido gran parte de su tejido social y de la memoria histórica del barrio, que no sería recuperada sino hasta el inicio de la reforma urbanística y la construcción del barrio cultural.

La idea de poner en marcha un proceso de regeneración urbana a partir de la instalación de una gran institución cultural arrancó a inicios de los ańos ochenta. Fue entonces que se conjugó la voluntad de resolver los problemas de degradación urbana y marginación social que padecía el barrio desde los años cuarenta, y a la vez dar uso a edificios infrautilizados y en proceso de degradación en el norte del barrio ${ }^{9}$. Así, la Diputación de Barcelona (DIBA) y el Ayuntamiento de Barcelona impulsaron la creación de una gran institución cultural que combinara diversos servicios culturales (museo, centro cultural, biblioteca, etcétera), siguiendo el modelo del Centro Pompidou parisino. Los responsables de estas administraciones públicas entendían que las infraestructuras culturales serían la imagen visible de la fuerte inversión pública que llevaban a cabo y, a la vez, atraerían inversiones privadas en el

Más concretamente, se trata de la recuperación del nombre medieval del barrio, que viene del árabe Rawal y quiere decir literalmente, "fuera de las murallas". No obstante, hay un consenso generalizado respecto de que hasta los años setenta nadie (ni las administraciones públicas) utilizaba este nombre para designar lo que ahora conocemos como Raval.

9 Este proyecto de creación de instituciones culturales se produjo, por lo tanto, en el marco de un proceso de regeneración urbana global del Raval, gestionado por una empresa mixta, PROCIVESA (Promoció Ciutat Vella, S.A.), que ha comportado el derribo de 500 edificios, la construcción de 1.200 viviendas públicas nuevas, la rehabilitación del 45\% de las viviendas y la apertura de tres grandes espacios públicos, así como otras muchas pequeńas intervenciones urbanísticas, que han supuesto una inversión pública total de 1.215 millones de euros (PROCIVESA, 2002). 
sector inmobiliario y comercial, las mismas que acabaron dinamizando este espacio urbano del centro de Barcelona (Subirats \& Rius, 2008).

El proyecto de la construcción de las grandes instituciones culturales se articuló a partir de la iniciativa del Ayuntamiento de Barcelona, a la que se sumaron la Diputación de Barcelona, la Generalitat de Catalunya y la Administración General del Estado. El proyecto fundador, denominado Centre de Cultura de la Casa de la Caritat, se dividió a mediados de los años ochenta en dos proyectos separados: el Centre de Cultura Contemporània de Barcelona (СсСв) y el Museu d'Art Contemporani de Barcelona (МАСвA), los cuales, junto a otras instituciones culturales, constituirían un importante clúster de cultura y servirían de buque insignia para simbolizar la transformación del Raval en un barrio cultural y denso distrito comercial y turístico.

Algunos autores han destacado las consecuencias negativas o gentrificadoras para la comunidad local de esta transformación (Degen, 2008; Degen \& García, 2012; Delgado, 2008; Miles, 2004). En estas visiones normalmente se tiende a contemplar la cultura como un elemento instrumentalizador y pasivo de la estrategia gentrificadora. Sin embargo, como veremos a continuación, el proceso ha sido más complejo y los sectores culturales, especialmente los emergentes y alternativos, han desempeñado un rol activo en la valoración del barrio para favorecer su conservación y fomentar la participación vecinal (Subirats \& Rius, 2008).

\section{El Raval como barrio cultural: transformación urbana}

Desde inicios del siglo xx el Raval ha poseído fama de barrio bohemio, y numerosas obras artísticas han sido creadas o inspiradas en él (Villar, 1997). Este sustrato preexistente se vio potenciado con la entrada, a partir de los ańos noventa, de jóvenes atraídos por su aura creativa y por la instalación de nuevas instituciones culturales ligadas al arte y la cultura contemporánea. No existen censos de la población artística actual, pero su presencia puede verse reflejada en la participación en Tallers Oberts de Ciutat Vella, desde el ańo 1996, de casi medio centenar de artistas (Foment de les Arts Decoratives, 2011). Estos Talleres Abiertos están situados en el norte del barrio, en las cercanías del clúster de instituciones culturales, estableciendo así con ellos una colaboración simbólica por proximidad. La presencia artística en el Raval se ha visualizado durante ańos con la presencia de street art (especialmente stencils y collages) en los muros del barrio, que hacen de marcador de la presencia de la comunidad artística y que representan una forma híbrida de activismo político y artístico.

Asimismo, en el Raval podemos observar el surgimiento, a partir de los años noventa, de asociaciones y pequeños locales que reproducen una subcultura bohemia, al margen de la Barcelona de clase media (Aisa \& Vidal, 2005). Se trata de una realidad que ha ido creciendo a medida que el Raval se consolidaba como barrio cultural y que alcanzó su cénit a finales de los años dos mil, con la creación de numerosos espacios alternativos y autogestionados. Entre ellos cabe destacar, como los más activos, El Almazén, Conservas o Riereta.net (Callén Moreu, 2011), que han colaborado con algunas iniciativas del clúster de instituciones culturales en ocasión de exposiciones o eventos (como la exposición de arte público "La ciutat de les paraules", o los festivales InMotion o Sonar). 
FIGURA 6 | Mapas de las instituciones y agentes culturales en el barrio del Raval (2008)

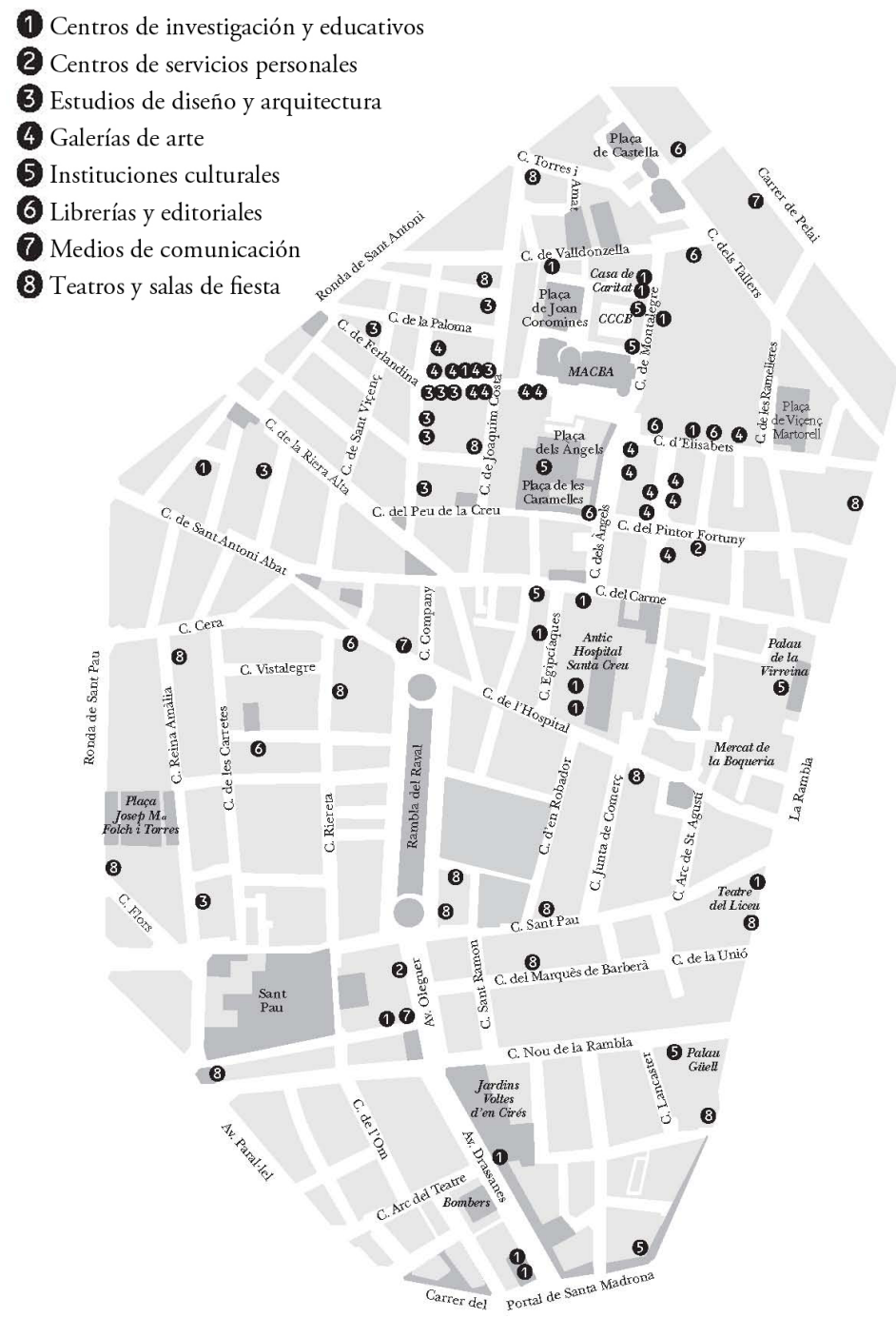

FUENTE MAPA ELABORADO POR LOS AUTORES

Esta escena alternativa buscó consolidarse a partir de diversas tentativas de ocupación del Teatro Arnau en 2006, una sala de espectáculos de la Avinguda del Paral.el (Avenida del Paralelo) y posteriormente del Teatro El Molino. En su manifiesto en pro de la liberación de la cultura, se denunciaba que "con la cultura, y de la mano de la especulación urbanística, se planifican desde los despachos zonas metropolitanas de interés cultural y se revalorizan los barrios del centro de la ciudad a partir de la instalación de faraónicos museos y centros de cultura institucional" (Espacio 
Liberado para la Cultura, 2006). Así, a la política cultural institucional y gentrificadora simbolizada por el clúster de instituciones culturales, se oponía una cultura libre, autogestionada e inclusiva por parte de la comunidad artística.

\section{FIGURA 7 Plantilla: sos especulación}

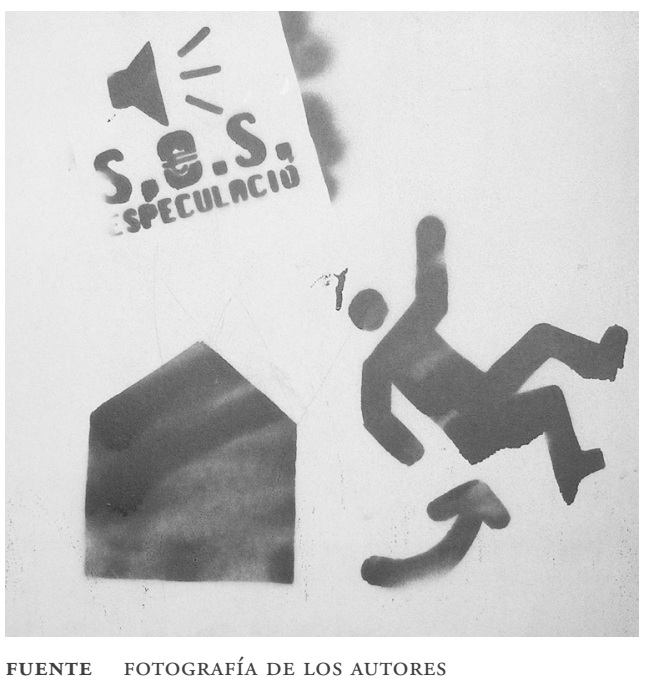

Por otra parte, el proceso de regeneración del Raval es, según el Ayuntamiento, uno de los ejemplos del modelo Barcelona en el que se ha intentado hacer participar a la comunidad local (Barber \& Pareja Eastaway, 2010). A pesar de que la estrategia de diseño e implementación de la regeneración urbana fue claramente top-down, con escasa participación de los vecinos del barrio (Blanco, 2009), las instituciones culturales del Raval han intentado desarrollar algunas vías de participación de los vecinos tradicionales, de los nuevos inmigrantes mayoritariamente de fuera de la Unión Europea y de la comunidad artística instalada en el barrio. En el inicio del MACBA, desde el servicio educativo se desarrollaron algunos proyectos como "La ciutat de les paraules" ("La ciudad de las palabras"), en que creadores animaron a los vecinos a escribir sus deseos en telas que luego exponían en sus balcones. Por otra parte, el сссв, partiendo de una misión fundacional orientada a la cultura de las ciudades estableció estrechas relaciones de colaboración con el sector cultural local, en general, y la comunidad artística del barrio, en particular, autoproclamándose en "antena y altavoz de los grupos emergentes de creadores de Barcelona" (entrevista al gerente сссв, 2004). No obstante, su característica de gran organización volcada a la proyección metropolitana e internacional, y su negativa a desarrollar una línea de trabajo cultural comunitario, lo ha aislado de la población inmigrante de origen extracomunitario o de los vecinos tradicionales del barrio, que lo perciben, en general, como un equipamiento cultural ajeno a ellos y como parte del proceso de pérdida de la identidad como comunidad local. 


\section{La coalición de comunidad local y sector cultural: comparando el Raval y Getsemaní}

En los procesos de transformación urbana en los barrios céntricos convergen diversos factores socioeconómicos que hacen confluir en un mismo espacio a diferentes esferas sociales, cuyos agentes pueden compartir interés en revalorizar un espacio urbano, pero con objetivos y dinámicas parcialmente divergentes. Así, en las siguientes figuras (8 y 9) podemos ver representados los tres ámbitos sociales principales que ejercen de marco a las transformaciones del barrio: la administración pública, la comunidad local y la economía de la creatividad y el conocimiento, a las que hemos superpuesto el elemento que hemos cifrado como central en este proceso: la cultura.

\section{FIGURA 8 Agentes, pautas de relación y alianzas en el barrio de Getsemaní (Cartagena de Indias) ${ }^{10}$}

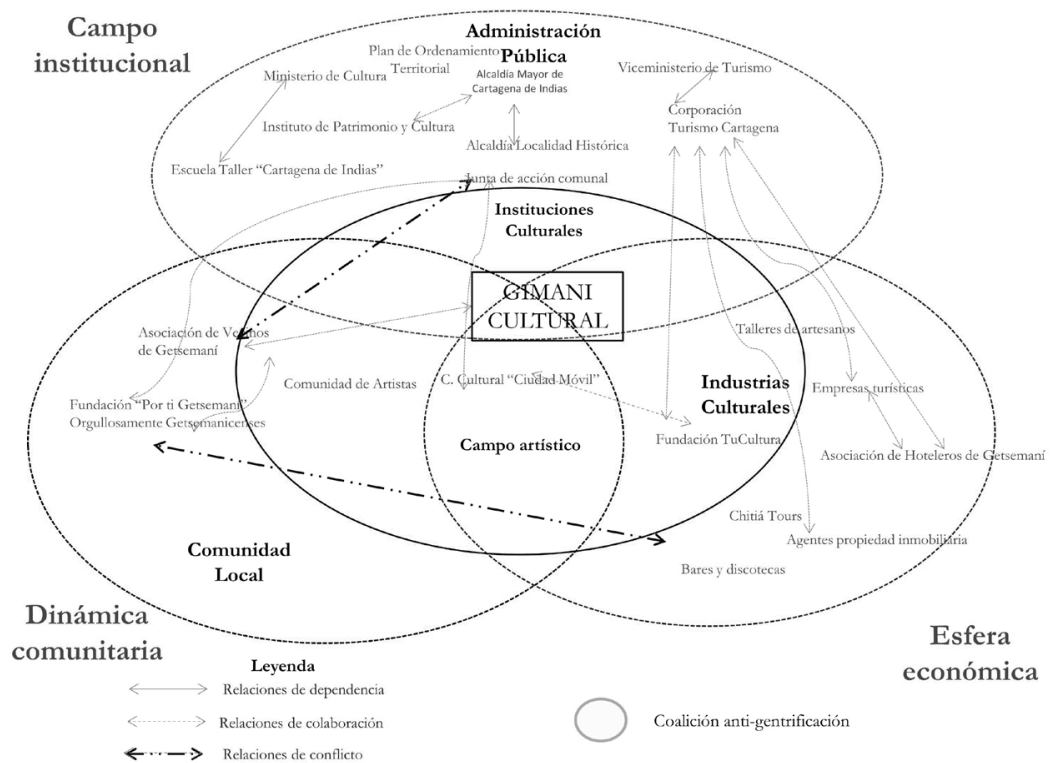

FUENTE FIGURA ELABORADA POR LOS AUTORES

La figura 8 muestra un barrio en el que han surgido numerosos agentes nuevos respecto al estadio anterior al proceso de regeneración urbana, de iniciativa de inversores privados, y que tiene como marco normativo el Plan de Ordenamiento Territorial (РОт) de la ciudad. Puede observarse, así, la presencia de agentes de la esfera económica ligados a la propiedad inmobiliaria, empresas turísticas, culturales o creativas (ocio, artesanías, pintura, etcétera); o bien nuevos comercios, que en

10 Los actores se han establecido a partir de las entrevistas cualitativas y la observación participante desarrollada en la investigación. Se ha diferenciado las relaciones de dependencia, colaboración y conflicto a partir del análisis del contenido de las entrevistas. 
diversos modos y grados han contribuido al proceso de gentrificación, no obstante que algunas organizaciones intentan combinar el desarrollo económico y turístico con la permanencia de la población local.

Debe destacarse también que, desde hace dos décadas, la Fundación Gimaní Cultural ejerce de elemento dinamizador y aglutinador de la identidad del barrio y es pieza esencial en la organización del Cabildo de Getsemaní, manifestación festiva y cultural central para el barrio. Paralelamente a la organización institucional, y de otros agentes clásicos de la organización de la comunidad local, han surgido actores como Orgullosamente Getsemanicenses y Por ti Getsemaní, que reivindican la identidad tradicional y la continuidad de los antiguos vecinos, oponiéndose al proceso de gentrificación. Sin embargo, estos sectores tradicionales no han establecido complicidades sólidas con el sector cultural alternativo, como el centro cultural autogestionado Ciudad Móvil. Así, se advierten enfrentamientos internos en los liderazgos de la comunidad local, al igual que una falta de consenso con los nuevos habitantes relacionados con actividades creativas. Esta falta de cohesión interna resquebraja las posibilidades de alianzas antigentrificación. Todo ello se produce en planes de desarrollo del barrio impulsados por las administraciones públicas bajo un prisma gentrificador, que favorecen claramente los intereses privados del sector turístico y empresarial.

FIGURA 9 Agentes, pautas de relación y alianzas en el barrio del Raval (Barcelona)

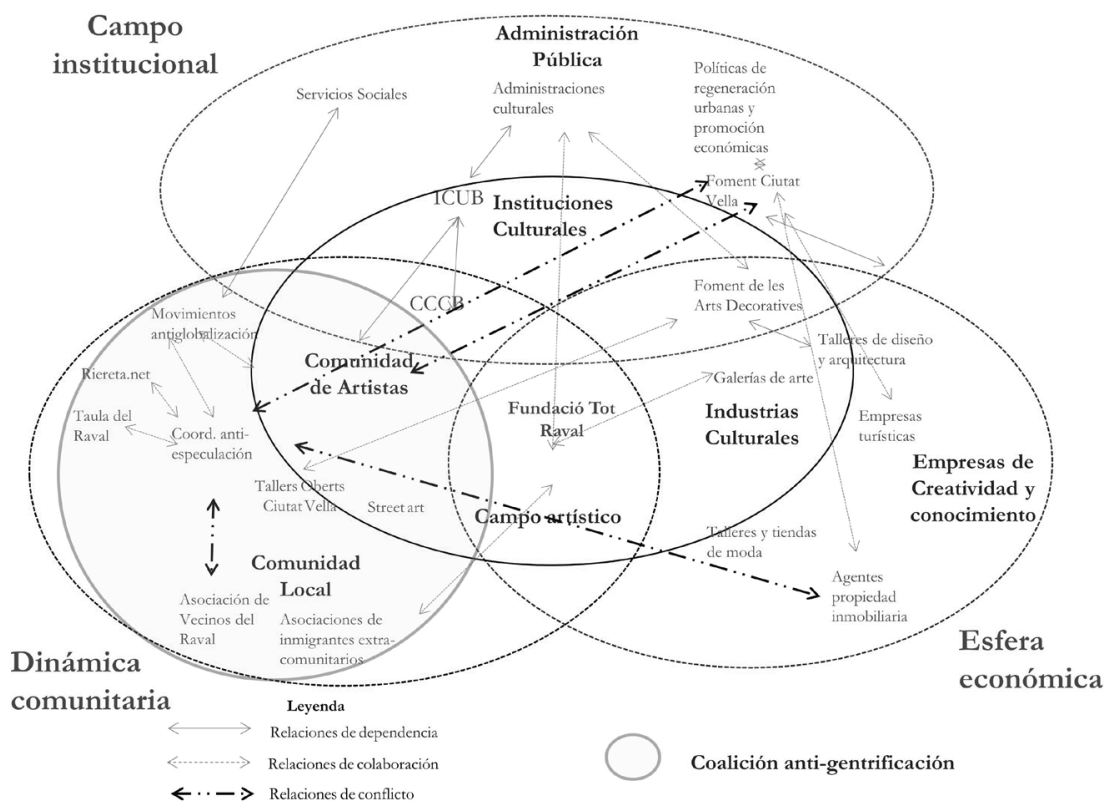

FUENTE FIGURA ELABORADA POR LOS AUTORES 
La figura 9 muestra la gran diversidad de actores existente en el barrio el Raval, conjunto que, sin embargo, podemos dividir en tres esferas sociales: el campo institucional (administraciones públicas y sus agencias), la esfera económica (empresas del ocio, turísticas, agentes de propiedades inmobiliarias) y la dinámica comunitaria (asociaciones vecinales). En medio de estas esferas debemos situar la esfera cultural, que hace intersección con las otras por la presencia de instituciones, empresas y asociaciones culturales.

El Ayuntamiento de Barcelona, consciente de la complejidad para gobernar este entramado de dinámicas de clusterización cultural, decidió crear en 2002 la Fundación Tot Raval, que pretende crear un marco estable de interacción y colaboración entre los agentes de los tres ámbitos sociales. Este marco, sin embargo, no es neutral, y Tot Raval se enfoca a convertirse en una coalición de todos los agentes a favor de la regeneración urbana (y de sus consecuencias socioeconómicas), que ejerza el rol de dinamización social y tienda puentes entre las grandes instituciones culturales y la comunidad local (Truñó, 2008). Frente a esto, los agentes más críticos con el proceso de transformación urbana consideraron que Tot Raval estaba orientada fundamentalmente a la promoción económica y que su vertiente social no era más que una fachada legitimadora, por lo que decidieron boicotearla. Así, asociaciones de artistas y espacios culturales (Conservas, Almazen, Estudio 08001), grupos de activistas (antiglobalización, antiespeculación, tecnoactivismo), asociaciones vecinales no vinculadas con el Ayuntamiento (Taula del Raval) y en parte las instituciones culturales (MACBA), han forjado coaliciones antigentrificación.

Los efectos de esta alianza pueden verse en sus programaciones culturales y actividades públicas, como los seminarios sobre Raval del MACBA, institución que, pese a su origen como motor del cambio urbano, se ha implicado en denunciar en sus actividades la gentrificación en el centro histórico de Barcelona a finales de los años dos mil (Delgado, 2008). Sin embargo, la voluntad de consolidar y dar visibilidad pública a esta alianza en el ańo 2006 a partir de la ocupación de los teatros abandonados del barrio para formar espacios libres para la cultura, no tuvo éxito y fueron desalojados por la policía, a pesar del notable apoyo ciudadano con el que contó (Espacio Liberado para la Cultura, 2006). Por otra parte, debe destacarse que esta coalición no ha conseguido incluir a todos los representantes de los habitantes tradicionales, sus asociaciones socioculturales tradicionales, los orfeones, como tampoco a las asociaciones de inmigrantes, colectivos que se han mantenido al margen de aquella coalición, debilitando así la resistencia a las dinámicas de gentrificación que todos padecen.

\section{Conclusiones}

Actualmente existe consenso sobre la importancia de la cultura en la regeneración de las ciudades (Evans, 2003; Pike, 2011). La mayor importancia del consumo, del turismo y de las industrias creativas en las economías urbanas ha amplificado más, si cabe, este rol de la cultura. En buena medida, tal proceso representa las transformaciones del capitalismo actual (Scott, 2007), puestas de manifiesto en las planificaciones urbanas y las dinámicas resultantes, especialmente en los barrios de los centros históricos (Rius-Ulldemolins, 2014). Una de estas dinámicas ha sido 
la gentrificación, es decir, la expulsión de los habitantes y la estandarización de la vida social en el espacio urbano, y la oferta comercial (Degen, 2003; 2008). Sin embargo, la cultura ha desempeñado otros roles, como la generación de nuevas identidades para barrios sobre cuyas calles y habitantes a menudo pesaba un largo estigma social y, paralelamente, la creación de nuevas marcas del espacio urbano ligadas a las creaciones culturales más avanzadas (Rius-Ulldemolins, 2014).

El caso de dos barrios como Getsemaní (Cartagena de Indias) y el Raval (Barcelona), a pesar de encontrarse en continentes y contextos políticos, económicos y sociales diversos, muestra la importancia de la cultura en los procesos de regeneración urbana y significativas coincidencias en las dinámicas económicas y sociales que produce. En ambos casos, la cultura ha permitido aliviar (aunque no hacer desaparecer del todo) el estigma de zonas degradadas y peligrosas, a la vez que ha conseguido poner en valor el patrimonio histórico-arquitectónico y revalorizar los estilos de vida y las tradiciones culturales y festivas de sus habitantes tradicionales. Sin embargo, cómo negar que a la vez ha generado fenómenos de gentrificación en ambos casos -más acentuados en el caso de Getsemaní, por la ausencia de una gobernanza del proceso-, que ponen en riesgo la diversidad social y cultural de estos barrios (Posso, 2015). Se trata de transformaciones impulsadas por agentes económicos interesados en la potenciación comercial, turística y residencial, que han visto en los procesos de desarrollo una oportunidad para captar las rentas generadas por el alza de precios y la revalorización de estos espacios urbanos (Harvey, 2005). Tales tendencias no han sido contrarrestadas por los planes urbanísticos o por las agencias públicas o mixtas (de capital público-privado) encargados de su desarrollo y de la supervisión en el cumplimiento de las normas establecidas.

En ninguno de los casos revisados el sector cultural ha quedado impasible frente a la situación de gentrificación, y diversos agentes de dicho sector se han implicado en defender la diversidad social y cultural del barrio. Y lo han hecho en parte porque también amenaza su propia supervivencia en el territorio (ante una mayor presión turística y el alza de los precios inmobiliarios), y en parte porque su actividad creativa se vincula simbólicamente a las tradiciones y dinámicas socioculturales de estas zonas. Así, hemos podido observar cómo se forjan coaliciones antigentrificación entre una parte de la comunidad local tradicional y los nuevos habitantes creativos. Estas alianzas son útiles para dar visibilidad social a las luchas de la comunidad local, para promover imágenes de los barrios alternativas a la visión oficial o turística, y para desarrollar planes y proyectos urbanos que operen como disyuntiva a la gentrificación. Con contradicciones y conflictos, tales alianzas se han desarrollado en ambos casos, aunque ciertamente con mayor densidad y dinamismo en el Raval que en Getsemaní. Ello puede ser explicado por una mayor densidad de agentes sociales y políticos en el caso del Raval y también porque las mismas administraciones públicas -especialmente la responsable de políticas e instituciones- han desarrollado espacios de encuentro y gobernanza de estos procesos en los que los movimientos sociales han podido participar, aunque sea de forma crítica y antagonista.

También podemos observar, en ambos casos, cómo la falta de consenso y colaboración entre los sectores culturales emergentes, las industrias culturales y las instituciones culturales debilita las coaliciones. En el caso de Barcelona se ha desarrollado 
una cierta alianza entre una institución cultural y los sectores emergentes, pero ello no ha fructificado en una sola voz del sector cultural. Tampoco se ha conseguido, en el caso de Getsemaní, generar un movimiento social unificado y un mensaje claro; la dispersión en diversos movimientos vecinales ha conseguido revalorizar en parte la identidad local y sus tradiciones, pero no trasmitir un mensaje claro frente al proceso de cambio urbano (Posso, 2015). Por otra parte, en ambos casos se ha detectado una fragmentación y a veces enfrentamiento en la misma comunidad local entre el sector de los residentes tradicionales y los nuevos residentes, o entre la comunidad local y las instituciones culturales. Ello se deriva de percibir la cultura solamente como un agente de la transformación urbana gentrificadora y no comprender que la cultura ofrece, de hecho, las herramientas para empoderarse y construir colectivamente escenarios alternativos a la gentrificación. Asimismo, la falta de unidad de la comunidad local y sus diferentes sectores sociales disminuye la capacidad de movilización y de generar una gobernanza del barrio realmente participativa. En este sentido, los organismos que teóricamente deberían ejercer este rol, como gobiernos institucionales del barrio o fundaciones privadas con participación de los agentes del barrio, o bien son escenarios de enfrentamiento o bien no consiguen reunir a estos diferentes agentes locales, actuando, en este sentido, una gobernanza más nominal que efectiva sobre el proceso de transformación.

En definitiva, el que las coaliciones antigentrificación tengan éxito depende también de una conciencia social y sensibilidad cultural que posibiliten ver cómo la capacidad de generar cultura y una marca urbana distintiva está ligada a la valorización del patrimonio inmaterial preexistente y del tejido social que lo ha producido. Es necesario crear certeza respecto de que, si bien con la gentrificación y la estandarización del espacio urbano se generan rentas a corto plazo para los especuladores e inversores, a largo plazo se agotará esta fuente de riqueza social y valor cultural.

Así, pues, si bien la cultura puede generar una tendencia gentrificadora, en el largo plazo puede ser también un factor de oposición a los fenómenos concomitantes a la gentrificación y un puntal para la sostenibilidad social y económica de unos barrios que, si bien ya no son los guetos populares anteriores a la transformación, tampoco están condenados a ser escenarios de cartón piedra orientados a los turistas. De hecho, pueden constituirse en una alternativa válida de vida urbana, en laboratorios de una nueva ciudad creativa y a la vez sostenible, participativa e inclusiva.

\section{Referencias bibliográficas}

Aguilera, M. \& Meisel, A. (2009). Tres siglos de historia demográfica de Cartagena de Indias. Bogotá: Banco de la República / Biblioteca Luis Ángel Arango.

Aisa, F. \& Vidal, M. (2005). El Raval: Un espai al marge. Barcelona: Editorial Base.

Ávila, F. (2011). Lo “afro" en el discurso turístico de Cartagena: subexposición y sobreexposición. En F. Ávila, R. Pérez \& Ch. Rinaudo, Circulaciones culturales. Lo afrocaribeño entre Cartagena, Veracruz y La Habana (pp. 189-213). México, D.F.: Publicaciones de la Casa Chata. 
Balibrea, M. P. (2004). Barcelona: del modelo a la marca. En Carrillo, J. et al. (Ed.), Desacuerdos 3. Sobre arte, politicas y esfera pública en el estado español. Barcelona: Arteleku, pp. 261271.

Barber, A. \& Pareja Eastaway, M. (2010). Leadership challenges in the inner city: Planning for sustainable regeneration in Birmingham and Barcelona. Policy Studies, 31(4), 393-411. doi: $10.1080 / 01442871003723309$

Belfiore, E. (2002). Art as a means of alleviating social exclusion: does it really work? A critique of instrumental cultural policies and social impact studies in the UK. International Journal of Cultural Policy, 8(1), 91-106. doi: 10.1080/102866302900324658

Belfiore, E. (2004). Auditing culture. The subsidised cultural sector in the new public management. International Journal of Cultural Policy, 10(2), 183-202. http://dx.doi.or $\mathrm{g} / 10.1080 / 10286630042000255808$

Bell, D. (1991). El advenimiento de la sociedad postindustrial: un intento de prognosis social. Madrid: Alianza.

Bianchini, F. (1991). City centres, city cultures: The role of the arts in the revitalisation of towns and cities. Londres: Centre for Local Economic Strategies.

Bianchini, F. (1993). Urban cultural policy in Britain and Europe: Towards cultural planning. Londres: Institute for Cultural Policy Studies.

Blakeley, G. (2005). Local governance and local democracy: The Barcelona model. Local Government Studies, 31(2), 149-165. doi: 10.1080/03003930500031959

Blanco, I. (2009). Gobernanza urbana y políticas de regeneración: el caso de Barcelona. Revista Española de Ciencia Política, (20), 125-146.

Borja, J. (2010). Luces y sombras del urbanismo de Barcelona. Barcelona: Editorial uoc.

Brida, J. G., Bukstein, D., Garrido, N. \& Tealde, E. (2010). Cruise passengers' expenditure in the Caribbean port of Call of Cartagena de Indias: A cross-section data analysis. Estudios y Perspectivas en Turismo, 19(5), 607-634. http://dx.doi.org/10.5367/ te. 2012.01153

Callén Moreu, B. (2011). Tecnoactivismo. La experiencia politica de riereta.net. Barcelona: Universitat Autònoma de Barcelona.

Casgrain, A. \& Janoschka, M. (2013). Gentrificación y resistencia en las ciudades latinoamericanas. El ejemplo de Santiago de Chile. Andamios. Revista de Investigación Social. Universidad Autónoma de la Ciudad de México, 10(22), 19-44. Disponible en http://www.redalyc.org/pdf/628/62828837002.pdf

Castells, M. (1989). The informational city: Information, technology, economic restructuring and the urban-regional process. Oxford: Blackwell.

Caraballo, C. (2000). Centros históricos de América Latina, una polémica de fin de siglo. En F. Carrión (Ed.), Desarrollo cultural y gestión en centros históricos (pp. 105-119). Quito: Flacso-Ecuador.

Carrión, F. (2007). El financiamiento de la centralidad urbana: el inicio de un debate necesario. En F. Carrión, (Ed.), Financiamiento de los centros históricos de América Latina y El Caribe (pp. 9-24). Quito: Flacso-Ecuador.

Contreras, Y. (2011). La recuperación urbana y residencial del centro de Santiago: nuevos habitantes, cambios socioespaciales significativos. EURE, 37(112), 89-113. Disponible en http://www.redalyc.org/articulo.oa?id=19619852005 
Contreras, E. (2014), Puerto Maravilla: la gentrificación del centro histórico de Río de Janeiro, Brasil. Coloquio Internacional Perspectivas del estudio de la gentrificación en México y Latinoamérica, Universidad Nacional Autónoma de México.

Corporación de Turismo de Cartagena de Indias (2014). Sistema de información turística de Cartagena. Cartagena de Indias: Corporación de Turismo de Cartagena de Indias.

Currid, E. (2007). The Warhol economy: How fashion, art, and music drive New York City. Princeton, NJ: Princeton University Press.

Currid, E. \& Williams, S. (2010). The geography of buzz: Art, culture and the social milieu in Los Angeles and New York. Journal of Economic Geography, 10(3), 423-451. doi: $10.1093 / \mathrm{jeg} / \mathrm{lbp} 032$

Degen, M. (2003). Fighting for the global catwalk: Formalizing public life in Castlefield (Manchester) and diluting public life in El Raval (Barcelona). International Journal of Urban and Regional Research, 27(4), 867-880. doi: 10.1111/j.03091317.2003.00488.x

Degen, M. M. (2008). Sensing cities: Regenerating public life in Barcelona and Manchester. Londres: Routledge.

Degen, M. \& García, M. (2012). The transformation of the 'Barcelona model': An analysis of culture, urban regeneration and governance. International Journal of Urban and Regional Research, 36(5), 1022-1038. doi: 10.1111/j.1468-2427.2012.01152.x

Delgadillo, V. (2009). Patrimonio urbano y turismo cultural en la Ciudad de México: las chinampas de Xochimilco y el Centro Histórico. Andamios. Revista de Investigación Social. Universidad Autónoma de la Ciudad de México, 6(12), 69-94. Disponible en http://www.redalyc.org/articulo.oa?id=62815957004

Delgado, M. (2008). La artistización de las políticas urbanas. El lugar de la cultura en las dinámicas de reapropiación capitalista de la ciudad. Scripta Nova: Revista Electrónica de Geografia y Ciencias Sociales, 12 (270 [69]). Disponible en http://www.ub.edu/geocrit/ sn/sn-270/sn-270-69.htm

De Mattos, C. et al. (2005). Reestructuración del mercado metropolitano de trabajo y cambios socioterritoriales en el Gran Santiago. Santiago: Informe de investigación proyecto Fondecyt 1040838.

Díaz, R. \& Paniagua, R. (1993). Getsemani. Historia, patrimonio y bienestar social en Cartagena. Cartagena de Indias: Coreducar.

Díaz, R. \& Paniagua, R. (1994). San Diego. Historia, patrimonio y gentrificación en Cartagena. Cartagena de Indias: Coreducar.

Doratli, N. (2005). Revitalizing historic urban quarters: A model for determining the most relevant strategic approach. European Planning Studies, 13(5), 749-772.

Espacio Liberado para la Cultura (2006). Abierto el nuevo espacio liberado para la cultura. Masala, 30, 4-5.

Evans, G. (2003). Hard-branding the cultural city-from Prado to Prada. International Journal of Urban and Regional Research, 27(2), 417-440. doi: 10.1111/1468-2427.00455

Featherstone, M. (1991). Consumer culture and postmodernism. Londres / Newbury Park, CA: Sage Publication. 
Ferreira, J. (2014). Violencia urbana, militarización del espacio y lucha por la ciudad de los megaeventos. Una mirada sobre las estrategias para la gentrificación de favelas en Río de Janeiro. Coloquio Internacional Perspectivas del estudio de la gentrificación en México y Latinoamérica, Universidad Nacional Autónoma de México.

Ferrer, F. \& Morillo, M. (2013). Getsemani. Patrimonio inmaterial vivo del centro histórico de Cartagena de Indias. Cartagena de Indias: Ministerio de Cultura-Asociación de Vecinos Getsemaní-Fundación Erigaie.

Fischer, C. S. (1995). The subcultural theory of urbanism: A twentieth-year assessment. American Journal of Sociology, 101(3), 543-577. doi: http://dx.doi.org/10.1086/230753

Florida, R. L. (2002). The rise of the creative class: And how it's transforming work, leisure, community and everyday life. Nueva York: Basic Books.

Foment de les Arts Decoratives (2011). Tallers oberts de ciutat vella. Barcelona: Foment de les Arts Decoratives.

García, B. (2004). Urban regeneration, arts programming and major events: Glasgow 1990, Sydney 2000 and Barcelona 2004. International Journal of Cultural Policy, 10(1), 103118. doi: 10.1080/1028663042000212355

García, B. (2004). Cultural policy and urban regeneration in western European cities: Lessons from experience, prospects for the future. Local Economy, 19(4), 312-326. doi: $10.1080 / 0269094042000286828$

Geissel, B. (2008). Do critical citizens foster better governance? A comparative study. West European Politics, 31(5), 855-873. doi: 10.1080/01402380802234516

Glass, R. (1964). London: Aspects of change report 3. Londres: Centre for Urban Studies, MacGibbon and Kee.

Gray, C. (2007). Commodification and instrumentality in cultural policy. International Journal of Cultural Policy, 13(2), 203-215. doi: 10.1080/10286630701342899

Harvey, D. (1989). From managerialism to entrepreneurialism: The transformation in urban governance in late capitalism. Geografiska Annaler. Series B, Human Geography, 71(1), 3-17. doi: $10.2307 / 490503$

Harvey, D. (2005). El arte de la renta: la globalización y la mercantilización de la cultura. En D. Harvey \& N. Smith (Eds.), Capital financiero, propiedad inmobiliaria y cultura (pp. 2958). Barcelona: Museu d'Art Contemporani de Barcelona.

Insulza, J. (2012). 'Latino-gentrificación' y su proceso de renovación urbana global en barrios históricos. Crónica de cambios anunciados desde Bellavista, Santiago. En J. Gutiérrez. (Ed.), Planeación, participación y gestión en los procesos urbanos actuales. Una visión iberoamericana (pp. 234-242). Toluca, México: Universidad Autónoma del Estado de México.

Insulza, J. (2014). Latino gentrificación y cambio socioespacial en la ciudad contemporánea. Coloquio Internacional Perspectivas del estudio de la gentrificación en México y Latinoamérica, Universidad Nacional Autónoma de México.

Insulza, J. (2012). 'Latino-gentrificación’ y su proceso de renovación urbana global en barrios históricos. Crónica de cambios anunciados desde Bellavista, Santiago. En J. Gutiérrez (Ed.), Planeación, participación y gestión en los procesos urbanos actuales. Una visión iberoamericana (pp. 234-268). Toluca, México: Universidad Autónoma del Estado de México. 
Janoschka, M., Sequera, J. \& Salinas, L. (2014). Gentrification in Spain and Latin America. A critical dialogue. International Journal of Urban and Regional Research, 38(4), 12341265. doi: $10.1111 / 1468-2427.12030$

Jordán, R. \& Carbonetti, M. (2007). Agenda urbana y financiamiento de centros y centralidades en América Latina y el Caribe: una relación deficitaria. En F. Carrión (Ed.), El financiamiento de los centros históricos de América Latina y el Caribe (pp. 5976). Quito: Flacso-Ecuador.

Julier, G. (1996). Barcelona design, Catalonia's political economy, and the new Spain, 19801986. Journal of Design History, 9(2), 117-127. doi: 10.1093/jdh/9.2.117

Julier, G. (2005). Urban designscapes and the production of aesthetic consent. Urban Studies, 42(5-6), 869-887. doi: 10.1080/00420980500107474

Julier, G. (2011). Design activism meets place-branding: Reconfiguring urban representation and everyday practice. En A. Pike (Ed.), Brand and branding geographies (pp. 221238), Cheltenham; Northampton: Edward Elgar.

Kagan, S. \& Hahn, J. (2011). Creative cities and (un)sustainability: From creative class to sustainable creative cities. Culture and Local Governance, 3: 1-2, 11-27. doi: http:// dx.doi.org/10.18192/clg-cgl.v3i1.182

Landry, Ch. \& Bianchini, F. (1995). The creative city. Nueva York / Londres: Demos. Disponible en http://www.demos.co.uk/files/thecreativecity.pdf

Lash, S. (1994). Economies of signs and space. Londres / Newbury Park, Ca: Sage Publication: Sage.

Lemaitre, M. C. \& Palmeth, T. (2001). Getsemaní: el último cono donde desembocan los vientos. Medellín: Lealon.

Lloyd, R. (2010). Neo-bohemia: Art and commerce in the postindustrial city. Nueva York / Londres: Routledge.

Majoor, S. (2011). Framing large-scale projects: Barcelona forum and the challenge of balancing local and global needs. Journal of Planning Education and Research, 31(2), 143-156. doi: $10.1177 / 0739456 \times 11402694$

Makhlouf, M. (2014). Aproximaciones a la gentrificación en el Río de Janeiro de los megaeventos deportivos. Actores, discusiones y resistencias. Coloquio Internacional Perspectivas del estudio de la gentrificación en México y Latinoamérica. México, D.F.: Universidad Nacional Autónoma de México.

Markusen, A. (1996). Sticky places in slippery space: A typology of industrial districts. Economic Geography, 72(3), 293-313. doi: 10.2307/144402

Markusen, A. \& Gadwa, A. (2010). Arts and culture in urban or regional planning: A review and research agenda. Journal of Planning Education and Research, 29(3), 379-391. doi: $10.1177 / 0739456 \times 09354380$

Markusen, A. \& Schrock, G. (2006). The artistic dividend: Urban artistic specialisation and economic development implications. Urban Studies, 43(10), 1661-1686. doi: $10.1080 / 00420980600888478$

Marshall, T. (1996). Barcelona - fast forward? City entrepreneurialism in the 1980s and 1990s. European Planning Studies, 4(2), 147-165. doi: 10.1080/09654319608720337

Marshall, T. (2000). Urban planning and governance: Is there a Barcelona model? International Planning Studies, 5(3), 299-319. doi: 10.1080/713672855 
Martí-Costa, M. \& Pradel i Miquel, M. (2012). The knowledge city against urban creativity? Artists' workshops and urban regeneration in Barcelona. European Urban and Regional Studies, 19(1), 92-108. doi:10.1177/0969776411422481

Mendes, S. (2007). El financiamiento de la revitalización urbana en América Latina: una revisión de la teoría y la práctica post 1980. En F. Carrión (Ed.), El financiamiento de los centros históricos de América Latina y el Caribe (pp. 60-77). Quito: Flacso-Ecuador,

Miles, M. (2004). Drawn and quartered: El Raval and the haussmannization of Barcelona. En M. Jayne \& M. Jayne (Eds.), City of quarters: Urban villages in the contemporary city (pp. 37-55). Aldershot, Humpshire, uk: Ashgate.

Montgomery, J. (2003). Cultural quarters as mechanisms for urban regeneration. Part 1: Conceptualising cultural quarters. Planning Practice and Research, 18(4), 293-293. http://dx.doi.org/10.1080/1561426042000215614

Muntaner, J. M. (2007). El modelo Barcelona. El Pais, 12-06, 2007, 56. Disponible en http:// elpais.com/diario/2007/06/12/catalunya/1181610445_850215.html

Novy, J. \& Colomb, C. (2013). Struggling for the right to the (creative) city in Berlin and Hamburg: New urban social movements, new spaces of hope? International Journal of Urban and Regional Research, 37(5), 1816-1838. doi: 10.1111/j.14682427.2012.01115.x

Parés, M., Bonet-Martí, J. \& Martí-Costa, M. (2012). Does participation really matter in urban regeneration policies? Exploring governance networks in Catalonia (Spain). Urban Affairs Review, 48(2), 238-271. doi: 10.1177/1078087411423352

Peck, J. (2005). Struggling with the creative class. International Journal of Urban and Regional Research, 29(4), 740-770. doi: 10.1111/j.1468-2427.2005.00620.x

Pike, A. (2011). Brands and branding geographies. Cheltenham, Northampton: Edward Elgar.

Posso, L. (2015). Getsemaní, casa tomada. Cartagena de Indias: Icultur.

procivesa (2002). Ciutat vella, ciutat constrü̈da, Barcelona: El Cep i la Nansa.

Rius-Ulldemolins, J. (2014). Culture and authenticity in urban regeneration processes: Place branding in central Barcelona. Urban Studies, 51(14), 3026-3045. doi: $10.1177 / 0042098013515762$

Rius, J. \& Subirats, J. (Dirs.) (2005). Del Xino Al Raval. Cultura i tranformació social a la Barcelona central. Barcelona, Centre de Cultura Contemporània de Barcelona Institut D'edicions.

Salinas, L. (2013). Gentrificación en la ciudad latinoamericana. El caso de Buenos Aires y Ciudad de México. Revista GeoGraphos-Giecryal, 4(44), 281-305. Disponible en http://web.ua.es/es/revista-geographos-giecryal/documentos/luis-salinas.pdf?noCache $=1363271617297$

Sánchez, M. V., Rius-Ulldemolins, J. \& Zarlenga, M. (2012). ¿Ciudad creativa y ciudad sostenible?: un análisis crítico del "modelo Barcelona" de políticas culturales. Revista Crítica de Ciências Sociais, (96), 31-50.. Disponible en http://dialnet.unirioja.es/ servlet/articulo?codigo $=4373351 /$ DOI $10.4000 /$ rccs. 5101

Scott, A. (2000). The cultural economy of cities. Londres / Thousand Oaks, CA / Nueva Delhi: Sage / Theory, Culture \& Society, Nottingham Trent University.

Scott, A. (2007). Capitalism and urbanization in a new key? The cognitive-cultural dimension. Social Forces, 85(4), 1465-1482. doi: 10.1353/sof.2007.0078 
Scott, A. (2010). Cultural economy and the creative field of the city. Geografiska Annaler: Series B, Human Geography, 92(2), 115-130. doi: 10.1111/j.1468-0467.2010.00337.x

Subirats, J. \& Rius, J. (2008). Del Xino al Raval. Cultura i transformació social a la Barcelona central: Barcelona: Editorial Hacer.

Subirós, J. (1998). El vol de la fletxa. Barcelona '92: Crònica de la reinvenció de la ciutat. Barcelona: Electa.

Subirós, J. (1999). Estrategias culturales y renovación urbana. Barcelona: Aula Barcelona.

Swyngedouw, E. (2005). Governance innovation and the citizen: The Janus face of governancebeyond-the-state. Urban Studies, 42(11), 1991-2006. doi: 10.1080/00420980500279869

Truñó, M. (2008). Experiencia de Tot Raval y algunas reflexiones sobre el trabajo comunitario. Revista de Educación Social (14-01-2008), (7-1), 11-18. Disponible en http://www. eduso.net/res/?b=10\&c=94\&n=245

Vanolo, A. (2008). The image of the creative city: Some reflections on urban branding in Turin. Cities, 25(6), 370-382. http://dx.doi.org/10.1016/j.cities.2008.08.001

Vázquez Montalbán, M. (1973). Los Mares del Sur. Barcelona: Planeta.

Villar, P. (1997). Hisoria y leyenda del barrio chino (1900-1992). Barcelona: La Campana.

Williams, S. \& Currid-Halkett, E. (2011). The emergence of Los Angeles as a fashion hub: A comparative spatial analysis of the New York and Los Angeles fashion industries. Urban Studies, 48(14), 3043-3066. doi:10.1177/0042098010392080

Wu, W. (2005). In Research W. B. P. (Ed.), Dynamic cities and creative clusters. Documento de trabajo del Banco Mundial 3509, febrero 2005. Washington DC: World Bank. http:// dx.doi.org/10.1596/1813-9450-3509

Zarlenga, M., Rius-Ulldemolins, J. \& Rodríguez Morató, A. (2013). Cultural clusters and social interaction dynamics: The case of Barcelona. European Urban and Regional Studies. 0969776413514592.

Zukin, Sh. (1989). Loft living: Culture and capital in urban change, Nueva York: Rutgers University Press. 